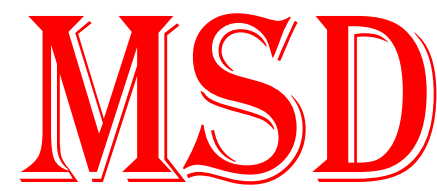

Medical Science and Discovery ISSN: 2148-6832

\section{Zinc levels in Beta-Thalassemia Major: A Review of the Literature}

\author{
Okan Dikker ${ }^{1}$, Emine Türkkan $^{2}$, Nevin Çetin Dağ ${ }^{2}$, Hüseyin Dağ $\breve{g}^{2,3}$ \\ 1 University of Health Sciences, Prof. Dr. Cemil Taşçığlu City Hospital, Dept of Biochemistry, Istanbul, TR \\ 2 University of Health Sciences, Prof. Dr. Cemil Taşçığlu City Hospital, Dept of Pediatrics, Istanbul, TR \\ 3 Istanbul University, Institute of Child Health, Dept of Pediatric Basic Sciences, Adolesance Health, Istanbul, TR \\ * Corresponding Author: Hüseyin Dă̆ E-mail: huseyindag2003@gmail.com
}

\section{ABSTRACT}

Objective: Zinc is an essential trace element for the body that is involved in various significant body functions such as protein synthesis, DNA synthesis, and cellular growth. It is found in almost every cell and plays an important role in the immune system, affecting both innate and acquired immunity. Patients with beta-thalassemia major are at risk of zinc deficiency. Beta-thalassemia major is an inherited disease caused by a reduction or complete absence of beta-globin chains and the affected patients need repeated blood transfusions to survive. Accordingly, it causes oxidative stress and tissue damage, alteration of antioxidant enzymes, and changes in other essential trace element levels due to iron overload. Zinc levels in beta-thalassemia major patients were reported to be significantly reduced in most of the studies. Serum zinc levels of the patients with beta-thalassemia major should be monitored regularly and zinc supplementation should be provided to these patients.

Keywords: Zinc, Beta-Thalassemia Major, Thalassemias, Review

\section{INTRODUCTION}

Zinc is an essential trace mineral, which is crucial for all living tissues, both as a structural component of proteins and because of its important role as a cofactor in enzyme catalysis. Zinc is actively involved in many metabolic activities in the human body such as protein synthesis, DNA synthesis, cellular growth, wound healing, and fertility. The importance of zinc in human body metabolism has been demonstrated by the consequences of zinc deficiency, such as impaired wound healing, reduced immune response, growth retardation, affected bone mineral density, impaired glucose tolerance, neurological disturbances, irritability, and deformed nails (1).

Zinc is found in high concentrations in animal products such as meat, fish, and egg and especially in seafood such as mussels. Zinc, which should be taken in a certain amount every day for optimal health, is found in all organs, tissues, and body fluids. Zinc plays a role in the functions of more than 300 metalloenzymes and transcription of more than 2000 genes involved in lipid, protein, and nucleic acid metabolism. It is well known that zinc is essential for many functions of the natural and acquired immune system against pathogens and tissue damage, and has a protective effect against the damages of free oxygen radicals (2).

The absorption of zinc takes place actively in the intestine, especially in the duodenum. Its maximum absorption occurs in the middle jejunum and ileum. Zinc is absorbed by enterocytes and goes through the bloodstream. There are special zinc carrier proteins that transport zinc into and out of the cell (3). About $80 \%$ of the zinc that passed into the plasma is bound to albumin, which functions as a major zinc carrier. Alfa-2 macroglobulin is also another important zinc-binding protein. Zinc, binds to albumin and alfa-2 macroglobulin and can pass through the liver, spleen, kidney, bone marrow, and erythrocytes, where its metabolism will occur rapidly. Excretion of zinc, which can pass into all fluid and membrane structures, is mainly through the feces, then bile, and renal route $(4,5)$. 


\section{Beta-thalassemia major}

Beta-thalassemia major is an autosomal recessive inherited disease that causes a severe clinical picture characterized by the absence or scarcity of the beta-globin chains of hemoglobin due to homozygous or double heterozygous mutations, excess alpha globin chains in erythrocytes, and imbalance in chain ratios. The incidence of the disease increases with consanguineous marriage (6). The severe imbalance of globin chain synthesis causes ineffective erythropoiesis, hemolysis, and anemia. Patients with betathalassemia major often have severe transfusion-dependent anemia. Transfusion therapy, which is the mainstay of treatment, allows normal growth and development and suppresses ineffective erythropoiesis, but leads to iron excess $(6,7)$. Excess iron causes oxidative damage and tissue siderosis. Iron overload causes various complications, including diabetes, hypothyroidism, hypogonadism, heart failure, short stature, and liver cirrhosis $(\mathbf{8}, \mathbf{9})$. Complications related to iron overloads, such as liver cirrhosis and heart diseases are the leading causes of morbidity and mortality in patients with transfusion-dependent beta-thalassemia major. Therefore, the main treatment strategy is; providing transfusion, reducing the iron burden, and increasing the life expectancy of these patients.

\section{Iron chelation therapy}

Iron chelation therapy is a lifelong requirement for patients with beta-thalassemia major (10). Iron-binding agents desferrioxamine, deferiprone, and deferasirox are used in treatment to prevent iron accumulation (11). However, iron chelating agents also eliminate various other essential elements, including zinc. Desferrioxamine has zinc binding affinity and increases urinary zinc elimination and hyperzincuria, resulting in gradual zinc depletion and growth disturbances, among other symptoms $(7,12)$. Chelation rapidly reduces liver iron, serum ferritin, and myocardial siderosis. Besides, chelation improves cardiac functions, reverses and prevents endocrine complications, reduces cardiac mortality, and increases survival $(\mathbf{1 0}, \mathbf{1 1})$.

\section{Zinc deficiency}

Zinc deficiency is common in developing countries where food is usually vegetable-based and rarely contains animal products. While zinc is easily absorbed by animal proteins, excessive plant meals lead to decreased zinc absorption due to its binding to phytates $(13,14)$. In such countries, zinc deficiency results in infection-related diarrhea and pneumonia, growth retardation, hypogonadism, increased mortality and morbidity due to impaired immune function $(13,15)$.

\section{Zinc levels in patients with beta- thalassemia major}

The relationship between zinc and beta-thalassemia major has been the subject of many studies. However, there are some differences between the results of the studies. Although some studies are reporting that zinc levels are not affected in patients with beta-thalassemia major $(12,16)$, the majority of studies support the decreased levels of zinc in these patients.
However, the variation in prevalence among these patients draws attention.

Some studies have reported zinc deficiency in betathalassemia major patients with a prevalence of $25 \%$ or less. Of these, Kwan et al reported zinc deficiency in only 3 of 68 beta-thalassemia major patients (17). In another study, a $10 \%$ prevalence of zinc deficiency was reported in patients with thalassemia major (18). Sultan et al (19) included 63 betathalassemia major children aged between 5 and 15 years who had been using desferrioxamine for at least 1 year and reported zinc deficiency (zinc levels $<50 \mu \mathrm{g} / \mathrm{dL}$ ) in 14 patients with a rate of $22.2 \%$. Besides, they also determined that the rate of zinc deficiency was higher in the male gender and those with a disease duration of more than 10 years. Fung et al (20) adopted a cut-off value of $<70 \mathrm{mg} / \mathrm{dL}$ for zinc deficiency and reported decreased zinc levels in $25 \%$ of patients with beta-thalassemia major and low bone density between the ages of 6 and 30 .

However, in many studies, zinc deficiency has been reported with a $60 \%$ or higher prevalence. Ferdaus et al (21) reported low serum zinc levels in $60 \%$ of beta-thalassemia patients. In the study conducted by Nidumuru et al (22), it was reported that the serum zinc levels of 35 transfusion-dependent betathalassemia major pediatric patients between the ages of 5 and 15 years were lower compared to healthy children with similar characteristics. They found serum zinc levels were $<60 \mu \mathrm{g} / \mathrm{dL}$ in $65 \%$ of the patients (26 patients) and evaluated these cases as hypozincemia. Based on their results, they stated that hypozincemia is common in patients with betathalassemia major. Mahyar et al (23) measured zinc levels in the serum of 40 patients with beta-thalassemia major under 12 years of age and reported that serum zinc levels of $<70 \mathrm{ug} / \mathrm{dL}$ in $26(65 \%)$ of them, while it was within the reference range in only 14 patients. In the study of Shamshirsaz et al (24), 220 cases with thalassemia were studied and the prevalence of zinc deficiency was reported as $79.6 \%$. Tabatabei et al reported that $84.8 \%$ of thalassemia major patients were having zinc deficiency. They emphasized that the cause of zinc deficiency in these patients was due to insufficient dietary intake (25). In a study conducted in Tehran Thalassemia Center (26), zinc deficiency was reported in $85.5 \%$ of 131 patients with beta-thalassemia major.

Arcasoy et al (27) reported that serum zinc levels were lower in all 30 beta-thalassemia major patients compared to controls. Mashhadi et al (28) reported severe zinc deficiency in all cases in their study on 333 transfusion-dependent patients with beta-thalassemia major. There were no cases of normal or increased zinc levels.

\section{Possible reasons for differences between studies}

Differences in the number of patients included in the studies, the differences in regular transfusion criteria or the duration of transfusions, the differences in chelation therapy, the use of different drug doses, and the differences in the duration of the disease may be the reason for the different prevalence of zinc deficiency in different studies. Besides, the fact that studies were conducted in regions with different socioeconomic statuses may have caused dietary differences in zinc levels $(29,30)$. Again, as stated in some studies, different zinc cut- 
off values draw attention and we believe that different prevalence between the studies may be caused by the different definitions of deficiency.

\section{Beta thalassemia major, zinc, and oxidative stress}

Oxidative stress is defined as the disruption of the balance between oxidants and antioxidants in the body due to excessive peroxide and free radical production. Oxidative stress occurs as a result of increased levels of lipid peroxides and free radical intermediates and a decrease in total antioxidant capacity in patients with beta-thalassemia major where frequent blood transfusions are required due to severe anemia $(31,32)$. Increased oxidative stress biomarkers are determined with decreased antioxidant levels in patients with beta-thalassemia major. Iron overload seen in patients with beta-thalassemia major may lead to decreased levels of trace elements such as vitamins and zinc as a result of oxidative stress caused by hemolysis and inflammation $(33,34)$.

The use of iron chelating agents in combination with antioxidants may aid in regulating oxidative status in patients with beta-thalassemia major $(31,32)$. Zinc has important antioxidant properties (35). Zinc has a protective role in the formation of free radicals and oxidative stress. Zinc is involved in the structure of superoxide dismutase, an antioxidant-effective enzyme, and metallothioneins that protect tissues from the harmful effects of free radicals (36).

Selective administration of essential trace elements such as zinc and antioxidant molecules to reduce the degree of oxidative damage and related complications in betathalassemia major may be beneficial in reducing oxidative stress in these patients.

Zinc is not stored by the body, so it is important to eat foods containing zinc every day to avoid deficiency. Zinc is also present in dietary supplements. Intervention strategies to combat zinc deficiency include zinc supplements, food supplements through the addition of zinc additives to food, and dietary alterations $(2,36)$.

\section{CONCLUSIONS}

In conclusion, in the light of the literature review, it is seen that zinc deficiency is present in most of the patients with beta-thalassemia major. Zinc levels were low in most studies. It should be kept in mind that zinc levels may be low in patients diagnosed with beta-thalassemia major who are under follow-up. In beta-thalassemia major patients who are transfusion-dependent and treated with chelators, serum zinc levels should be monitored and prophylactic zinc supplements should be considered in the routine management of these patients.

Author Contributions: OD, ET, NÇD, HD: Study design literature search and Data collection, HD: Article writing and revisions.

Financial \& competing interest's disclosure: The authors have no relevant affiliations or financial involvement with any organisation or entity with a financial interest in or financial conflict with the subject matter or materials discussed in the manuscript. This includes employment, consultancies, honoraria, stock ownership or options, expert testimony, grants or patents received or pending, or royalties.

Ethical approval: The study was conducted according to the guidelines of the Declaration of Helsinki and approved by Local Ethical Committee.

Conflict of interest: The authors declared no potential conflicts of interest with respect to the research, authorship, and/or publication of this article. This research did not receive and specific grant from funding agencies in the public, commercial, or not-for-profit sectors.

\section{REFERENCES}

1. Ackland ML, Michalczyk A. Zinc deficiency and its inherited disorders -a review. Genes Nutr. 2006;1(1):41-9.

2. Hemmens B, Goessler W, Schmidt K, Mayer B. Role of bound zinc in dimer stabilization but not enzyme activity of neuronal nitric-oxide synthase. J Biol Chem. 2000;275:35786-91.

3. Gammoh NZ, Rink L. Zinc in Infection and Inflammation. Nutrients. 2017;9(6):624.

4. Lu J, Stewart AJ, Sadler PJ, Pinheiro TJT, Blindauer CA. Albumin as a zinc carrier: Properties of its high affinity zinc-binding site. Biochem Soc Trans. 2008;36:1317-21.

5. Mocchegiani E, Costarelli L, Giacconi R, Cipriano C, Muti E, Malavolta M. Zinc-binding proteins and immunosenescence. Exp Gerontol. 2006;41:1094-107.

6. Cunningham M. The thalassemias. In: Orkin SH, Nathan DG, Ginsburg D, Look AT, Fisher DE, Lux SE, editors. Nathan and Oski's Hematology of Infancy and Childhood, 7th edition. Philadephia: Saunders Elsevier; 2009. p.1015-106.

7. Dehshal MH, Hooghooghi AH, Kebryaeezadeh A, Kheirabadi M, Kazemi S, Nasseh A, et al. Zinc deficiency aggravates abnormal glucose metabolism in thalassemia major patients. Med Sci Monit. 2007;13(5):235-9.

8. Galanello R, Origa R. Beta-thalassemia. Orphanet J Rare Dis. 2010;5:11.

9. Cunningham MJ, Macklin E, Neufeld EJ, Cohen AR. Complications of B-thalassemia major in North America. Blood. 2004;104:34-9.

10. Weatherall DJ, Clegg JB. Management and prognosis in the thalassemia syn- dromes. 4th ed. Oxford, UK: Blackwell Scientific; 2001. p:630-85.

11. Ceci A, Mangiarini L, Felisi M, Bartoloni F, Ciancio A, Capra M, et al. The man- agement of iron chelation therapy: preliminary data from a national registry of thalassaemic patients. Anemia. 2011;2011:435683.

12. Mehdizadeh M, Zamani G, Tabatabaee S. Zinc status in patients with major $\beta$ thalassemia. Pediatr Hematol Oncol. 2008;25(1):49-54.

13. Yakoob MY, Theodoratou E, Jabeen A, Imdad A, Eisele TP, Ferguson $\mathrm{J}$, et al. Preventive zinc supplementation in developing countries: impact on mortality and morbidity due to diarrhea, pneumonia and malaria. BMC Public Health. 2011;11(3):23.

14. Gibson RS, Ferguson EL. Nutrition intervention strategies to combat zinc deficiency in developing countries. Nutr Res Rev. 1998;11(1):11531 .

15. Yu M, Lee WW, Tomaretal D. Regulation of $\mathrm{T}$ cell receptor signaling by activation-induced zinc influx. J Exp Med. 2011; 208(4):775-85.

16. Kosarian M, Valaee N, Mahdyyanee A. Do the desferal receiver thalassemic patients have zinc deficiency?. J Mazandaran Univ Med Sci. 2000;26(10):1-6. 
17. Kwan EY, Lee AC, Li AM, Tam SC, Chan CF, Lau YL, et al. A crosssectional study of growth, puberty and endocrine function in patients with thalassaemia major in Hong Kong. J Paediatr Child Health. 1995;31(2):83-7.

18. Moafi A, Mobaraki G, Taheri SS, Heidarzadeh A, Shahabi I, Majidi F. Zinc in thalassemic patients and its relation with depression. Biol Trace Elem Res. 2008;123(1-3):8-13.

19. Sultan S, Irfan SM, Kakar J, Zeeshan R. Effect of iron chelator desferrioxamine on serum zinc levels in patients with beta thalassemia major. Malaysian J Pathol. 2015;37(1):35 -8

20. Fung EB, Kwiatkowski JL, Huang JN, Gildengorin G, King JC, Vichinsky EP. Zinc supplementation improves bone density in patients with thalassemia: a double-blind, randomized, placebo-controlled trial1-3. Am J Clin Nutr. 2013;98:960-71.

21. Ferdaus MZ, Hasan AK, Shekhar HU. Analysis of serum lipid profiles, metal ions and thyroid hormones levels abnormalities in betathalassaemic children of Bangladesh. $J$ Pak Med Assoc. 2010;60(5):360-4.

22. Nidumuru S, Boddula V, Vadakedath S, Kolanu BR, Kandi V. Evaluating the role of zinc in beta thalassemia major: a prospective case-control study from a tertiary care teaching Hospital in India. Cureus. 2017;9(7):e1495.

23. Mahyar A, Ayazi P, Pahlevan AA, Mojabi H, Sehhat MR, Javadi A. Zinc and copper status in children with beta $\neg$ thalassemia major. Iran J Pediatr. 2010;20 (3): 297-302.

24. Shamshirsaz AA, Bekheirnia MR, Kamgar M, Pourzahedgilani N, Bouzari N, Habibzadeh M, et al. Metabolic and endocrinologic complications in beta-thalassemia major: a multicenter study in Tehran. BMC Endocr Disord. 2003;3(1):4

25. Tabatabei M, Kamkar M, Habibzadeh MR. Metabolic and endocrine complications in beta-thalassemia major; a multicenter study in Tehran. Boshehr Med J. 2003;5(1):72-3.

26. Bekheirnia MR, Shamshirsaz AA, Kamgar M, Bouzari N, Erfanzadeh G, Pourzahedgilani N, et al. Serum zinc and its relation to bone mineral density in beta-thalassemic adolescents. Biol Trace Elem Res. 2004;97(3):215-24.
27. Arcasoy A, Canatan D, Sinav B, Kutlay L, Oğuz N, Şen M. Serum zinc levels and zinc binding capacity in thalassemia. J Trace Elem Med Biol. $2001 ; 15: 85-7$

28. Mashhadi MA, Sepehri Z, Heidari Z, Shirzaee E, Kiani Z. The prevalence of zinc deficiency in patients with thalassemia in South East of iran, sistan and baluchistan province. Iran Red Crescent Med J. 2014;16(8):e6243.

29. Quirolo K, Vichinnky E. Hemoglobin disorders. In: Behraman RE, editor. Nelson Textbook of Pediatrics. 18th ed. Philadephia: Saunders 2007. p.2033-9.

30. Lukenn JN. The thalassemia and related disorders. In: Richard Lee GR, Foeuster J, Lukens J, Parakeras F, Green J, Rodgers GM, editors. Wintrobes clinical hematology. 18th ed. Philadelphia: Lippincott, Williams \& Wilkins: 1999. p.1406-35.

31. Pavlova LE, Savov VM, Petkov HG, Charova IP. Oxidative stress in patients with beta-thalassemia major. Prilozi. 2007; 28(1):145-54.

32. Ghone RA, Kumbar KM, Suryakar AN, Katkam RV, Joshi NG. Oxidative stress and disturbance in antioxidant balance in beta thalassemia major. Indian J Clin Biochem. 2008;23(4):337-40.

33. Claster S, Wood JC, Noetzli L, Carson SM, Hofstra TC, Khanna R, et al. Nutritional deficiencies in iron overloaded patients with hemoglobinopathies. Am J Hematol. 2009;84(6):344-8.

34. Anastassopoulou J, Anifantakis B, Anifantakis ZA, Dovas A, Theophanides $\mathrm{T}$. The role of free radical reactions with haemoglobin and thalassaemia. J Inorg Biochem. 2000;79( 1-4):327-9.

35. Powell SR. The antioxidant properties of zinc. J Nut. 2000;130(Supp 1):1447-54.

36. Rostan EF, DeBuys HV, Madey DL, Pinnell SR. Evidence supporting zinc as an important antioxidant for skin. Int J of Dermatol. 2002;4:60611 . 